\title{
Smart fire monitoring system for a city: design and development
}

\author{
Dr. Evans B. Sansolis, Engr. Karen Alinor J. Dumpit, Dr. Cheryll Ann N. Feliprada \\ West Visayas State University, Philippine
}

\begin{abstract}
All Fire Alarm Systems essentially operate on the same fundamental principle and framework. It provides audible and visual alarm signals. An alarm is raised if a sensor detects smoke or heat, warns people that there may be a fire, and evacuate the premises immediately. Consequently, concerned individuals may call the fire department to mitigate the emergency at which, at this point of time, the firefighter's Emergency Respond Time (ERT) is vital. ERT is one of the contributing factors to how much fire will consume lives and, or properties. In worst cases, an entire building turns into ashes, lives taken because of a slow ERT. Then there are these casual "false-alarms" caused by the false-positive readings of the installed Fire Alarm Systems. These false alarms cause mass panic and consume firefighters' valuable time and resources. The instances mentioned above are a few reasons why there is a need to implement an efficient city-wide fire alarm system.

This study focused on the design, development and testing of a wide-area Smart Fire Monitoring System comprised of major parts, the devices and the system software. Specifically, this study aimed to develop a smart fire alarm device using the Agile Prototyping Methodology (APM) and employ Agile Software Development Methodology (ASDM) for the development of the Smart Fire Monitoring System Software (SFMSS). For the development of the smart fire alarm device, the proponents assembled necessary sensors, electrical components, microcontrollers, and other electrical modules to create a working smart fire alarm device that abled to detect smoke; detect temperature spikes; detect the existence of fire; broadcast a GPS coordinates to the fire department; transmit and receive data through RF signals using long-range radio frequency (RF) module and SMS technology; and, be functional and operational under Low Power mode. Concomitant with this device is its system software, SFMSS, to manage and process the broadcasted data. SFMSS is a centralized system developed for the fire department to monitor the city for a fire outbreak.
\end{abstract}


SFMSS continuously communicates with the fire alarm devices to autonomously monitor fire presence via radio frequency and process SMS notifications containing GPS coordinates, convert them into a readable address, and plot it in a city map in the event of a fire emergency. The proponents conducted a Stress and Reliability Test on the smart fire alarm device and Product Evaluation for Quality, Efficiency, and Usability with the Bureau of Fire Protection Region 6 for the entirety of the system.

\section{Introduction}

Frequent occurrence of urban fires is casual and rampant in any part of the world today (Masoumi et al., 2019). Problematic cooking tools, faulty electrical wirings, flammable gas and fluids, matches, and lighters in the hands of playful children can cause tremendous damage to lives and properties if those mentioned above will result in uncontrollable fire (National Safety Council, 2018). To caution the general public, the Philippines Bureau of Fire Protection and Management designated the month of March as Fire Prevention Month. An action that is due to the statistical analysis on historical data that it is during this month that fire incidents mostly occur. In 2017 alone, Philippines encountered 14,000 fire breakouts, taking 304 human lives and turning P7.8B worth of property into ashes (COA, 2018). In 2018, Starting January 1 up to February 28 of the same year, the Bureau of Fire Protection and Management has registered 1,758 emergency fire breakout incidents all around the country, with a record of 22 death casualties, and over one billion pesos property loss. According to the Bureau of Fire Protection and Management statistical data, short-circuit in electrical wirings, unextinguished cigarette butts, and unattended flamed stoves, are the most common reasons for a fire outbreak country (Ferrer et al., 2020).

Residential properties in an urban area are always prone to a disastrous fire, which can cause a tragic loss of lives or/and properties (Wisner et al., 2014). BFP statistical data reports that $90 \%$ of the Philippine urban area residencies do not have fire monitoring devices (Velasco, 2013). Furthermore, although it is mandated by Philippine law that every commercialized establishment should own a smoke alarm, a substantial $80 \%$ proportion of those smoke alarms do not work (Ferrer et al., 2020). Thus, the consequence of a residential fire is often monumental and tragic, resulting in significant losses. Fire alarms, which supposedly protect people from a possible fire outbreak by giving off the warning, can casually fail humanity by its false fire detection (Bandlow et al., 2017). This false positive alarm causes inconveniencies rather than protection. False alarms affect consumers' trust in these early warning devices, which is why adaption is sluggish. This dilemma in a fire alarm is one of the many challenges developers encounter in making fire detection devices (Deng et al., 2011).

All Fire Alarm Systems essentially operate on the same fundamental principle and framework. That is, all fire alarm system provides audible and visual alarm signals (QiuBo, 2019). If a sensor detects smoke or heat, an alarm is triggered to alert people that there may be a fire, and an immediate evacuation plan may be enforced to protect lives. A fire system that protects property, and protects lives, is an additional asset (Chen et al., 2013). However, fire alarms are created to satisfy the two critical requirements: one is for protecting assets and property, and most importantly, the preservation of life (CPSC, 
2016). As a consequence of the strict rules and local government building codes and SOPs, the life-protection objective of fire prevention has increasingly become more important. Moreover, with the breakthrough in the information technology sector, specifically in wireless telecommunications, fire alarm system technology extends the different range of technological adaptation wherein fire alarm systems have become increasingly complex and sophisticated these years (QiuBo, 2019).

The context discussed gave rise to this study, which aimed to develop a citywide Smart Fire Monitoring System that includes fire monitoring devices and its companion Smart Fire Monitoring System Software (SFMSS). Specifically, this study intended to develop the smart fire alarm device using the Agile Prototyping(APM) and employ Agile Software Development Methodology (ASDM) for the development of the Smart Fire Monitoring System Software (SFMSS).

\section{Materials and Methods}

For the development of the smart fire alarm device, the proponents assembled necessary sensors, electrical components, microcontrollers, and other electrical modules to create a working smart fire alarm device that abled to detect smoke; detect temperature Spikes; detect the existence of fire; broadcast a GPS coordinates to the fire department; transmit and receive data through RF signals using long-range radio frequency (RF) module and SMS technology; and, be functional and operational under Low Power mode. The developed SFMSS autonomously monitored the Smart Fire Alarm devices set up in selected urban establishments through radiofrequency. It processed SMS notifications containing GPS coordinates broadcasted from an alarm-triggered Smart Fire Alarm Device. The system software automatically converted the GPS coordinate into a readable address location and plotted it in a city map to pinpoint the fire incident location.

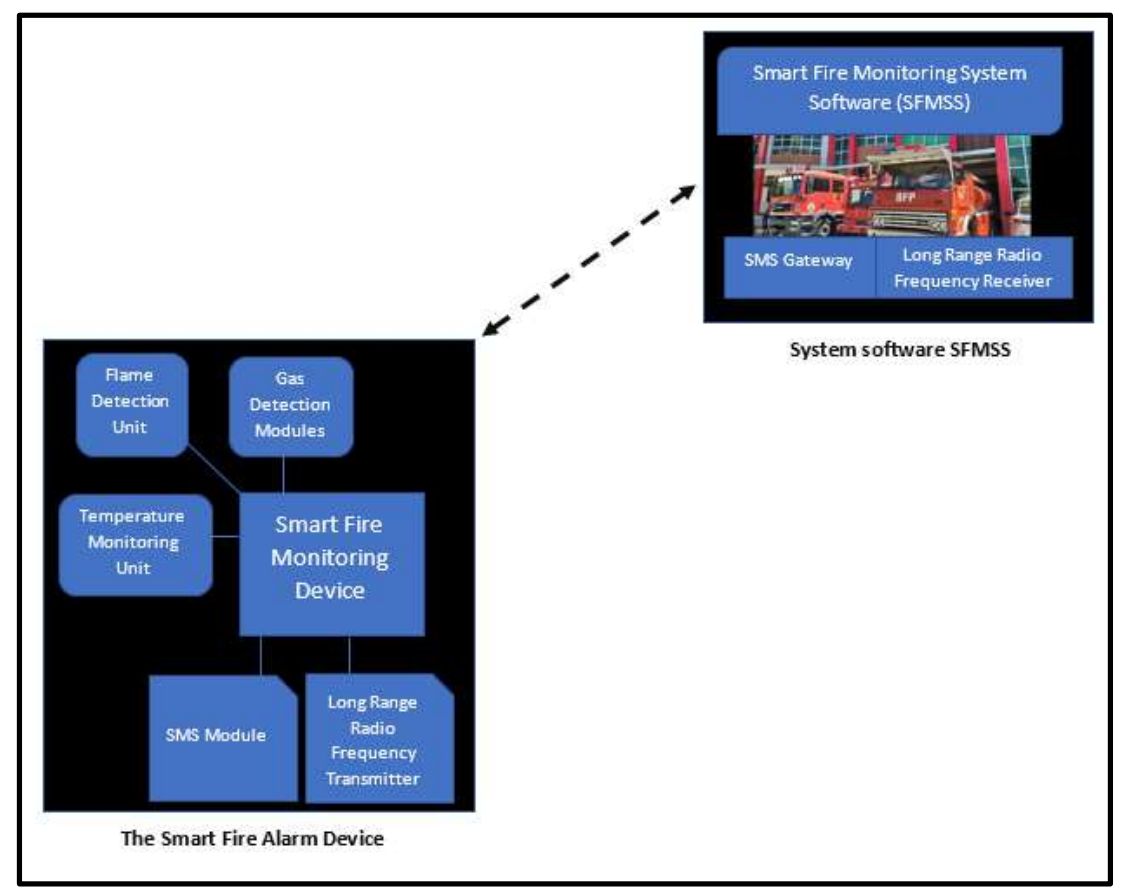

Figure 1. Birds-eye-view of the Smart Fire Monitoring System 
Figure 1 is the proposed conceptual framework of the Smart Fire Monitoring System. In this framework, a fire alarm device will measure the gas, temperature, and light intensity (for Flame detection) in the surrounding areas. These sensors continuously receive environmental data and then forward it to the device microchip. The gas, temperature, and light data collected by the sensors will be used to detect the presence of fire. In the event of smoke or fire, an alarm will be triggered, pushing the device to broadcast SMS GPS location information through radio frequency and SMS gateway to Smart Fire Monitoring System Software (SFMSS).

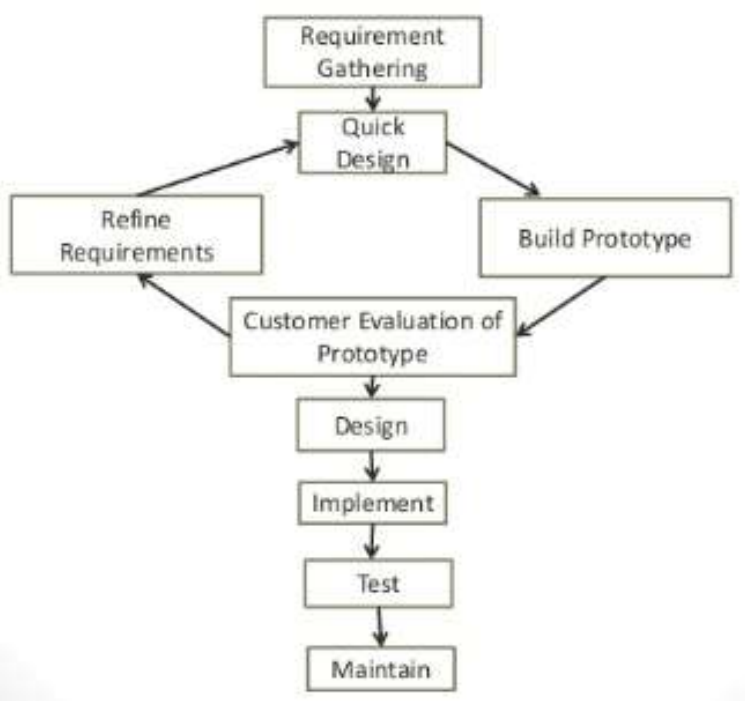

Figure 2. Agile Prototyping

This developmental research was made possible even under a time constraint because of the prototyping model methodology. One universally accepted product prototyping model adopted in this development project is the Agile Prototyping Design Methodology. Using the Agile Prototyping Design Methodology, the developer builds prototypes as soon as the requirements for a particular fire alarm module are collected. This procedure is iterated several times until a fully functional fire alarm system is deployed and captures the simple system and user requirements. In general, the Smart Fire Monitoring System prototype was constructed as part of the prototyping technique to determine the requirements and solution. Then these prototypes were subjected to tests, retests, and further evaluation with the target users and performed appropriate and necessary adjustments were. The advantage of employing the prototype approach in this development project was that the customers' requirements were confirmed in less time and effort. During the entire developmental stage of the Smart Fire Monitoring System, the risk of wasting time and a significant investment in hardware and software components is decreased.

The developed Smart Fire Monitoring System device relied on different sensors integrated into one smoke and fire detection component. Materials used include NRF24L01+PA+LNA RF Module with SMA Antenna, Nano V3.0 ATmega328P Board, Gas Modules (MQ-9, MQ-2), Flame Sensor, DH22, Broadband Stick, Sim808 Module. 
Both Liquid Petroleum Gas leakage and smoke are detected with the Gas Modules (MQ-9, MQ-2) and smoke sensor. The main reason gas sensors were included in this system is that LPG gas leaks are hazardous, and the detection of LPG can improve fire detection system functionality. For example, a fire outbreak may result if a leak is discovered while temperatures are incredibly high. All of the sensors in smart fire monitoring devices have integrated thresholds established. Once SFMSS detects the sudden spike relative to thresholds (either the readings are equal to the threshold or are slightly above), a positive fire identification is made. It triggers an alarm for the fire department. SFMSS processes the broadcasted messages into a readable address and plots them in a city map for the fireman's reference.

The SMART FIRE ALARM has an efficient, automated, and straightforward process in detecting fire. The gas sensors modules, flame sensor unit and the temperature sensor, which is integrated into the microcontroller, will keep reading the gas, infrared intensity, and the temperature of the environment as long as it has electrical power.

If the level of flame sensors' infrared readings increases up to more than 500units, the microcontroller will trigger the buzzer and the LEDs to buzz for the fire alarm. Also, temperature sensor DHT22 will keep on monitoring the room temperature. If the room temperature increases up to 40 degrees Celsius, the DHT22 will detect it and trigger the microcontroller to send an alarm using the LED lights and the buzzer. The SMS Module will be triggered to send location when smoke is detected. The Diagram below is a flowchart of how the SMS module will be activated.

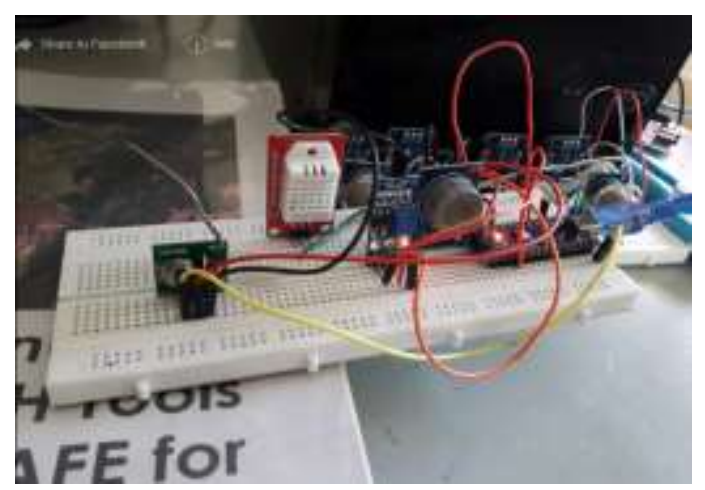

Figure 3. The Smart Fire Monitoring Device (Prototype version 1)

MQ gas Sensors, Temperature Sensor Light Intensity Sensor

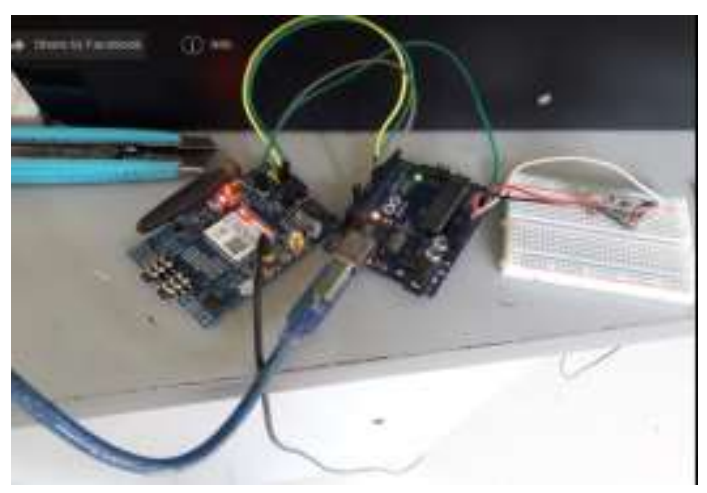

Figure 4. The Smart Fire Monitoring Device (Prototype version 1)

SMS Module and an ATMEGA 328 Microcontroller 
MQ gas Sensors, Temperature Sensor Light Intensity sensors (Figure 3) have been electrically connected to an SMS Module and ATMEGA 328 Microcontroller (Figure 4) for detecting smoke and fire.

So that the Smart Fire Alarm System device will function accordingly, an embedded system software using $\mathrm{C}++$ language was developed and uploaded in ATMEGA 328 microcontroller. Test and retest were performed to guarantee that every electrical part was fully functional, with a big emphasis on the gas, temperature, and fire detection units.

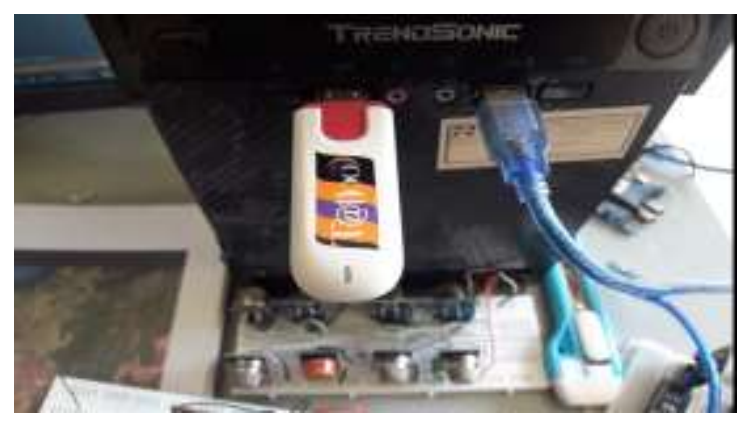

Figure 5. SMS Modem for the Bureau of Fire Protection SFMSS

The temperature and light data collected by the cost-effective fire alarm sensors will be used to detect the fire. Moreover, these sensors will receive and send data continuously to the device microchip. In the existence of smoke, an alarm will be triggered, pushing the device to broadcast SMS location information to the Bureau of Fire Protection central office SFMSS. Figure 7 is an SMS modem that receives the broadcast alert message which came from the fire alarm device.

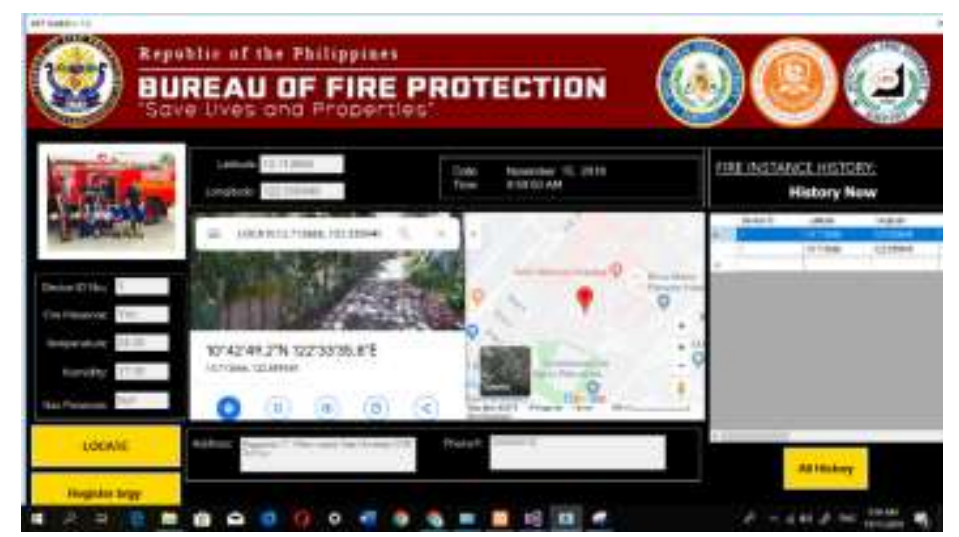

Figure 6. Smart Fire Alarm System Software (SFMSS) 

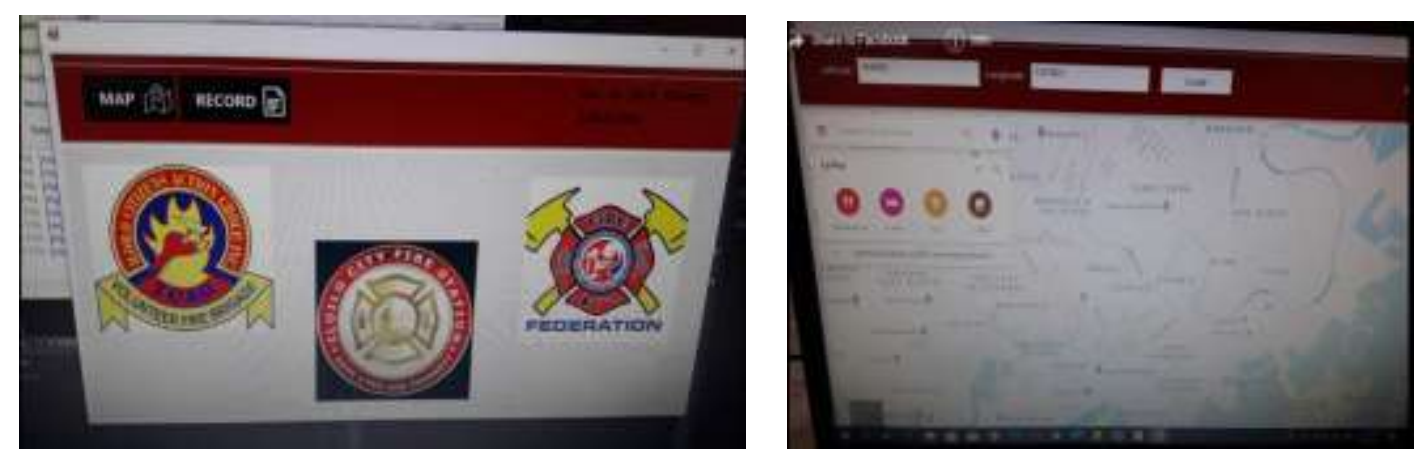

Figure 7. Smart Fire Monitoring System Homepage and view map for the Bureau of Fire Protection

A Smart Fire Monitoring System Software (SFMSS) (Figure5) in a server of the local fire department (Bureau of Fire Protection) was developed to monitor the fire alarm device's status.

\section{Results and Discussion}

Various testing was carried out to confirm that every sensor units are accurate before being incorporated into the primary smart fire alarm device. Each sensor was put through its paces on its own through Unit testing. Then finally, the smart fire alarm device was tested to demonstrate its reliability in fire detection functionality. The Stress and Reliability Test findings are tabulated below:

GAS Module: The smart fire alarm device gas detection module was tested for functionality. Combustible gas was produced using a cigarette lighter. The test results are shown in the table below.

\begin{tabular}{|l|l|l|l|}
\hline $\begin{array}{c}\text { Gas Module } \\
\text { Readings }\end{array}$ & \multicolumn{1}{|c|}{$\begin{array}{c}\text { Sensor } \\
\text { Threshold: }\end{array}$} & \multicolumn{1}{|c|}{ Action } & Remark \\
\hline $0 \mathrm{ppm}$ & $400 \mathrm{ppm}$ & SFMSS did not alarmed & $\begin{array}{l}\text { This is the expected } \\
\text { output }\end{array}$ \\
\hline $380 \mathrm{ppm}$ & $400 \mathrm{ppm}$ & SFMSS alarmed & $\begin{array}{l}\text { A sudden spike in } \\
\text { reading. This is the } \\
\text { expected output. }\end{array}$ \\
\hline $530 \mathrm{ppm}$ & $400 \mathrm{ppm}$ & SFMSS alarmed & $\begin{array}{l}\text { Readings are } \\
\text { greater than the } \\
\text { threshold. This is } \\
\text { the expected. }\end{array}$ \\
\hline
\end{tabular}

Performance Testing: Based on a speed metric, performance testing was conducted to determine the notification service (SMS alert) and the radio frequency broadcast. Once a fire was discovered, it was critical for the smart fire monitoring device to send SMSs and RF broadcasts to the SFMSS in a timely manner. A stopwatch was used to study and record the length of time that passed between the detection of a fire and the delivery of an alarm to a mobile phone in this test. The results are listed below. 


\begin{tabular}{|c|c|}
\hline Notification & $\begin{array}{l}\text { Time Interval Between Trigger And SMS } \\
\text { Receive Time }\end{array}$ \\
\hline SFMSS SMS Alert 1 & 5 seconds \\
\hline SFMSS SMS Alert 2 & 5 seconds \\
\hline SFMSS SMS Alert 3 & 5 seconds \\
\hline Average Time & 5 seconds \\
\hline
\end{tabular}

\begin{tabular}{|l|l|}
\hline Notification & $\begin{array}{l}\text { Time Interval Between Trigger And RF } \\
\text { Broadcast Receive Time }\end{array}$ \\
\hline SFMSS RF Broadcast Alert 1 & 2 seconds \\
\hline SFMSS RF Broadcast Alert 2 & 2 seconds \\
\hline SFMSS RF Broadcast Alert 3 & 2 seconds \\
\hline Average Time & 2 seconds \\
\hline
\end{tabular}

In this performance testing, the average broadcast receiving time for SFMSS to get the text notification was roughly 5 seconds. Additionally, the average time for SFMSS to receive the $\mathrm{RF}$ broadcast signal is at 2 seconds.

Prototype Integration Testing: This test was conducted in a controlled environment with the smart fire alarm device subjected to a real-life fire scenario to test if the system worked properly. An ordinary clothe ignited to produce smoke, heat, and flame. This test's outcome can be seen here:

\begin{tabular}{|c|c|c|c|c|c|}
\hline $\begin{array}{l}\text { Gas } \\
\text { Modules } \\
\text { (ppm) }\end{array}$ & $\begin{array}{l}\text { Smoke } \\
(\mathrm{ppm})\end{array}$ & $\begin{array}{l}\text { Temperature } \\
\text { (Deg. } \\
\text { Celsius) }\end{array}$ & $\begin{array}{l}\text { Infrared Sensor } \\
(\mathrm{Cd})\end{array}$ & $\begin{array}{l}\text { Fire } \\
\text { Emergen } \\
\text { cy Status }\end{array}$ & $\begin{array}{l}\text { Expect } \\
\text { ed } \\
\text { Result }\end{array}$ \\
\hline \multirow[t]{3}{*}{$\begin{array}{l}214 \mathrm{ppm} \\
\text { (Low) }\end{array}$} & $\begin{array}{l}\text { 100ppm } \\
\text { (Low) }\end{array}$ & 26.8 & 380 & None & None \\
\hline & $\begin{array}{l}\text { 344ppm } \\
\text { (High) }\end{array}$ & $\begin{array}{l}42.5 \text { (Sudden } \\
\text { Spike of } \\
\text { temp.) }\end{array}$ & $\begin{array}{l}470 \text { (Sudden } \\
\text { spike in IR } \\
\text { readings) }\end{array}$ & Alarm & Alarm \\
\hline & $\begin{array}{l}\text { 160ppm } \\
\text { (Low) }\end{array}$ & $\begin{array}{l}52 \text { (Extreme } \\
\text { and Sudden } \\
\text { Spike of } \\
\text { temp.) }\end{array}$ & $\begin{array}{l}515 \text { (High IR } \\
\text { readings) }\end{array}$ & Alarm & Alarm \\
\hline \multirow[t]{3}{*}{$\begin{array}{l}\text { 420ppm } \\
\text { (Medium) }\end{array}$} & $\begin{array}{l}\text { 512ppm } \\
\text { (High) }\end{array}$ & 48.0 & 332() & Alarm & Alarm \\
\hline & $\begin{array}{l}\text { 140ppm } \\
\text { (High ) }\end{array}$ & 27 & $\begin{array}{l}650 \text { (Extremely } \\
\text { High IR } \\
\text { readings) }\end{array}$ & Alarm & Alarm \\
\hline & $\begin{array}{l}\text { 440ppm } \\
\text { (High) }\end{array}$ & 46 & $\begin{array}{l}460 \text { (Medium } \\
\text { IR readings; } \\
\text { But considered } \\
\text { as sudden spike } \\
\text { in IR readings) }\end{array}$ & Alarm & Alarm \\
\hline
\end{tabular}


User Acceptability Testing: The user acceptance questionnaire below was used to assess the user acceptability of the Smart Fire Monitoring System.

CITYWIDE SMART FIRE MONITORING SYSTEM

Please rate the following software characteristics. The objective of this survey is to evaluate the quality of the developed software.

ALL INDIVIDUAL RESPONSES WILL REMAIN CONFIDENTIAL.
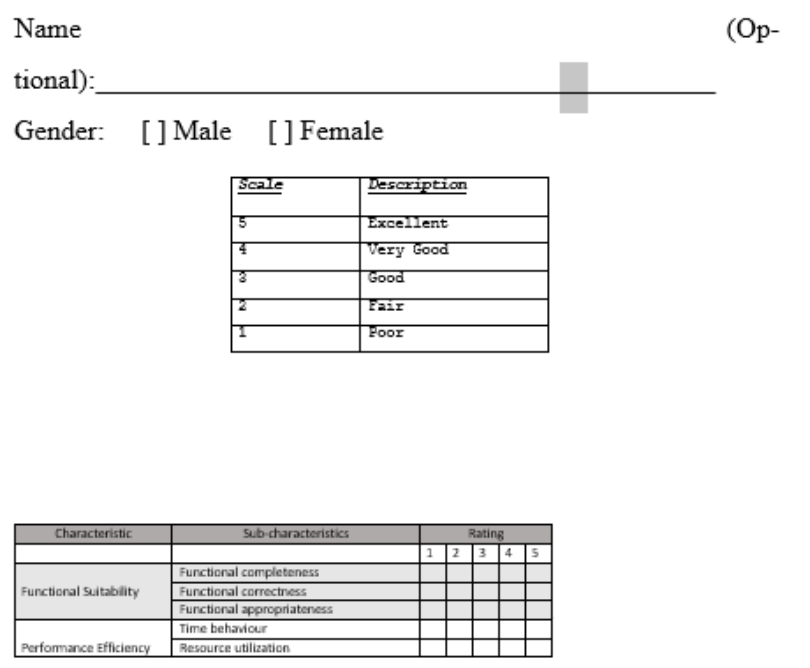

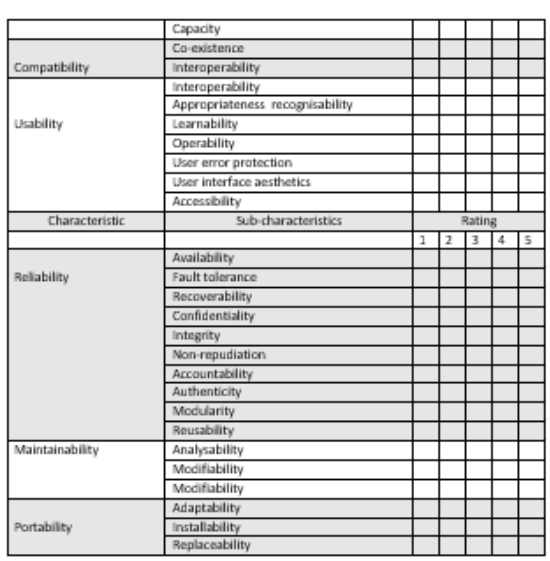

Type of Test: User Acceptability

Number of Respondents: 10 Region 6 Bureau of Fire and Protection Representatives Overall Score (Based on Likert Scale): 4 (Very Good)

The evaluators from the Region 6 Bureau of Fire Protection acknowledged that the Smart Fire Monitoring System Device could be instrumental in the efficient and timely detection of a fire breakout.

\section{Conclusion and Recommendations}

This study, which aimed to create an open-source intelligent fire alarm system utilizing Agile Prototyping Design Methodology, was completed, tested, and evaluated satisfactorily. The assembled open-source sensors, electrical components, microcontrollers, and other electrical modules were able to detect smoke, detect temperature spikes, detect the presence of fire, broadcast GPS coordinates to the fire department, transmit and receive data via RF signals using a long-range radio frequency (RF) module and SMS technology, and be functional and operational in Low Power mode. A stress test was also performed to assess the device's stability and a reliability test to 
determine its consistency, particularly in terms of measurement repeatability. A user product review was undertaken for Quality, Efficiency, and usability to assess the user acceptability level. Furthermore, various issues connected to fire detection and response were recognized during this research and development project, particularly during the prototype phase. Budget allocation and the unaffordability of some electrical parts were two challenges, and there was a lack of understanding about the need to install these monitoring devices in building premises.

Based on the findings of the research and the challenges encountered throughout the study's testing and evaluation, the following recommendations were made: As a first step toward a faster reaction time to fire occurrences, stakeholders in BFP fire department services should use the technique described in this study for fire detection. Also, a separate mobile application can be created to cater to a broader range of stakeholders. It is also recommended to include in the further development of this system the robotics technology for fire intervention, such as a fire-fighting bot that can communicate with the SFMSS after a fire is detected as the first line of defense before fire-fighting servicemen arrive, this is a positive step toward full automation of fire detection and mitigation. Lastly, it is recommended to encourage funding organizations to sponsor this study for product improvement and commercialization.

\section{References}

[1] Bandlow, A., Jones, K. A., Brown, N. J. K., \& Nozick, L. K. (2017). The impact of false and nuisance alarms on the design optimization of physical security systems. Advances in Intelligent Systems and Computing, 497, 189-201. https://doi.org/10.1007/978-3-319-41956-5_18

[2] Chen, R. X., Zhang, X. Q., Peng, C. Y., \& Z̄hang, H. Y. (2013). A study on design and implementation of remote fire monitoring system for buildings. Procedia Engineering, 52, 56-59. https://doi.org/10.1016/j.proeng.2013.02.105

[3] Commission on Audit. (2018). BFP's Capability of Safeguarding the Populace from Destructive Fires Hampered by Scarce Resources, and Gaps in the Procurement, Construction of Fire Stations, and Maintenance of Fire Trucks. Bureau of Fire Protection Modernization Program.

[4] CPSC. (2016). Where Should Smoke Alarms be Better G ood CPSC staff recommends the following: (Issue July). https://www.cpsc.gov/s3fspublic/SmokeAlarmWhyWhereandWhichCPSCPub559RevisedJuly2016PostRevi ew $\% 282 \% 29$.pdf

[5] Deng, T., Huang, F., Lu, Y., \& Liu, S. (2011). A complex fire monitoring system based on Ethernet. 7th International Conference on Wireless Communications, Networking and Mobile Computing, WiCOM 2011, June. https://doi.org/10.1109/wicom.2011.6040463

[6] Ferrer, O. G., Instructor, M., Education, J., \& State, C. (2020). EXTENT OF THE IMPLEMENTATION OF THE FIRE PREVENTION PROGRAMS OF THE BUREAU OF FIRE PROTECTION APARRI FIRE. 9(7), 33-44.

[7] Masoumi, Z., Genderen, J. van L., \& Maleki, J. (2019). Fire risk assessment in dense urban areas using information fusion techniques. ISPRS International 
Journal of Geo-Information, 8(12). https://doi.org/10.3390/ijgi8120579

[8] National Safety Council. (2018). IDENTIFYING THE CAUSES OF FIRE. In Medical Teacher (Vol. 6, Issue 3, pp. 106-107). https://doi.org/10.3109/01421598409019413

[9] QiuBo. (2019). Intelligent Development of Building Fire Monitoring System. Journal of Physics: Conference Series PAPER. https://doi.org/10.1088/1742$6596 / 1325 / 1 / 012099$

[10] Velasco, G. N. (2013). Epidemiological Assessment of Fires in the Philippines, 2010-2012.

[11] Wisner, B., Blaikie, P., Cannon, T., \& Davis, I. (2014). At risk: natural hazards, peoples vulnerability and disasters. At Risk: Natural Hazards Peoples Vulnerability and Disasters, 1-471. https://doi.org/10.4324/9780203714775 